\title{
The Need for Diversity, Equity, Inclusion, and Social Justice in the Southwest Athletic Trainers' Association
}

\author{
Meredith Decker, PhD, LAT, ATC* \& Shaketha Pierce, MS, LAT, ATC $\dagger$ \\ *University of Texas at Arlington, Arlington, TX; †Newman Smith High School, Carrollton, TX \\ Moderator: S. Andrew Cage, MEd, LAT, ATC
}

Key Phrases

Patient-centered care; LGBTQIA

Full Citation

Decker $M$, Pierce $S$. The need for diversity, equity, inclusion, and social justice in the southwest athletic trainers' association. Clin Pract Athl Train. $2021 ; 4(3)$ : 5-9.

https://doi.org/10.31622/2021/0004.3.2.

\section{EDITORIAL}

The Southwest Athletic Trainers' Association (SWATA) is excited to begin this new partnership with Clinical Practice in Athletic Training. As part of this partnership, the SWATA Free Communications and Research Committee provides double-blinded peer review abstracts from credentialed athletic trainers who presented their works in the Free Communications Program at the Annual SWATA Symposium. Out of an abundance of caution, the 2021 symposium was held virtually, and those free communications presentations were disseminated via social media.

The SWATA Mission Statement states that the purpose of the organization is to enhance the quality of healthcare for the physically active; to promote and advance the athletic training profession; to promote a better working relationship among those who work toward care and prevention of athletic injuries; enhance the healthcare of persons served by the membership; safeguard and advance the membership; and to promote the free exchange of information with SWATA. To this end, the SWATA Free Communications and Research Committee has entered into collaborative efforts with the district's Lesbian, Gay, Bisexual, Transgender, and Queer (LGBTQ+) Advisory Committee and the Ethnic Diversity Advisory Committee. Through these efforts, the hope is to promote a community of athletic trainers who embrace their collective roles as clinicians, educators, and scholars, working toward a common goal of enhancing the holistic health of physically active individuals from all populations.

At the 2021 SWATA Virtual Symposium, the district expressed the explicit need for continuing professional development and programming to improve diversity, equity, inclusion, and social justice in athletic training. To this end, the SWATA Free Communications Committee interviewed our district LGBTQ+ Advisory Committee Chair, Meredith Decker, and Ethnic Diversity Advisory Committee Chair, Shaketha Pierce. The SWATA Free Communications and Research Committee Chair, Andrew Cage, gained insight into the committees' current initiatives.

Cage: Please tell the readers the roles and responsibilities of these committees within SWATA, and the athletic training profession as a whole.

Pierce: The great thing about the Ethnic Diversity Advisory Committee is that our role is that we get to bring awareness to ethnically diverse situations for patients and athletic trainers. We get to serve as advocates for information and research relating to healthcare issues and conditions that affect the health of physically active ethnic minority patients. We identify and address issues related to cultural distinctions in healthcare delivery. We advocate for recruitment and retention of athletic trainers from ethnic minorities, and bring attention to healthcare disparities affecting ethnic minority patients. 
Decker: The role of the LGBTQ+ Advisory Committee is to serve as an advisory committee Our main goal as a committee is to facilitate inclusive athletic training practices. We specifically do so by providing resources on the wide range of LGTBQ+ topics. Whether that is creating and disseminating articles or infographics, putting together research, or just sharing the most relevant resources tied to LGBTQ+ issues in the community.

Cage: What are some of the challenges the patient populations you serve encounter in healthcare?

Pierce: The challenges that the populations that I serve encounter tend to be health disparities. When these patients have been sent to physician, the physician is not always aware of the cultural conditions that these patients are faced with. The patients may not receive the best care possible due to different biases healthcare providers have. There are also language barriers patients may encounter. Some patients do not have insurance or have other financial issues leading to them being turned away. Along with that, we also have to make sure that we send our patients to healthcare providers who we know will give them the best care. We also have to make sure that our patients are getting the best patient-centered care from us and other healthcare providers.

Decker: For the LGBTQ+ patient population, this is a really broad category of individuals. There are a lot of different challenges that the community as a whole faces. It relates to the identities within the LGBTQ+ community. Whether it is an identity related to gender or sexual orientation within the community. It depends on those factors what challenges those people will face. Overall, the LGBTQ+ community is still looking to gain equality in this country. I think that spans into healthcare as well. We can see that nowadays with the various anti-transgender and anti-LGBTQ+ legislation that is occurring within our country. Specific to that, there are a lot of issues related to access to healthcare. A lot of people in the LGBTQ+ community have trouble finding inclusive healthcare providers that are willing to treat their individualized patient needs. It really boils down to providers not truly understanding those patient needs and getting to know the patient on that individual level and providing patient centered care. Another big issue is that patients and patients may not feel like they are in a safe and inclusive environment. They may not feel like they can be themselves or disclose their identities for fear of repercussions from an acceptance standpoint and access to healthcare standpoint.

Cage: What are some of the challenges the clinician populations you serve encounter in their clinical practice?

Pierce: A lot of challenges ethnically diverse clinician populations face come down to the first challenge that usually comes up, microaggressions. It could have to do with the clinician's hair, how they speak, how they express themselves. A clinician may talk with their hands or elevate their voice, which can be perceived as aggressive by those who do not understand how the clinician expresses themselves. That does not mean the clinician has attitude, which is just how they express themselves. It is often misperceived.

Decker: A lot of LGBTQ+ athletic trainers may feel that there are negative repercussions if they are their authentic selves in their patient care settings. That may limit them from being out or sharing their authentic selves. They may be out in their personal lives, but not in their work lives for fear of acceptance or their job security. It is an unfortunate reality that people can still be fired for being LGBTQ+ in their work environment. Also, not being fully understood in the identities that we all share in the LGBTQ+ community. This impacts us as an individual person, and we want our coworkers and others to take that into account. I would say the biggest challenge is the feeling that 
there is not a safe space to be clinicians, similar to our patients.

Cage: How does someone who is unfamiliar gain a better understanding of what athletic trainers and patients from ethnic minorities and the LGBTQ+ community deal with while trying to do their jobs or participate in sports?

Pierce: I would say for ethnic minorities the biggest thing is, last year the National Athletic Trainers' Association (NATA) came out with the Listen First Initiative. That would be the first thing, listen first. If a patient comes in and is trying to tell you that they feel a certain way about care they have received or someone they have encountered, the biggest thing is to listen and try not discredit what they are telling you. Try not to say "I didn't see that". You may not have, because it did not happen to you. While you are listening, work to be an active listener. Make sure you are listening to understand, not to try to counter what you are being told. Also, work to be able to have uncomfortable conversations. With ethnically diverse populations, we are used to being the only ones in the room. We are used to being uncomfortable. Often times, when others we speak with are uncomfortable it makes them feel a certain way, and they are not use to that. So work to get used to having uncomfortable conversations and having those encounters where you can ask questions in that safe space that Meredith mentioned earlier. Next, make sure to remove personal opinions and beliefs. Make sure that whenever you go into your clinic or facility, whatever person beliefs that you have do not keep you from treating your patients the way they should be treated. Even if there is something you do not agree with, your patient should never know that.

Decker: I am going to echo the first point that Shaketha made about listening and understanding. I think that is the first step regardless of which community or patient we are talking about. It is really the ability to try to understand people on an individual level that makes us patient centered clinicians. Also, become educated more about the LGBTQ+ community as a whole; dive into understanding different populations. This may just start with some of the basics of understanding the difference between gender identity and sexual orientation. Try to understand the specifics, but also the community as a whole and the challenges that they face. The part about education that I really want to emphasize is that it has to be self-driven to fully understand the LGBTQ+ population. We cannot fully rely on those within the LGBTQ+ community to share their experiences and to direct our learning for us. We have to be a self-directed learner where you seek out that information on your own and then can come back to the patients and providers that you are working with and show that you have gained and are using that understanding.

Cage: What specific knowledge and skills do you think athletic trainers need in order to best serve a patient population that includes members of ethnic minorities and the LGBTQ+ community?

Pierce: I would say one of the skills would be interpersonal skills, to be able to have conversations with patients and colleagues and be able to ask about families, life, and to get beyond the typical patient information. Another skill is cultural competence, a lot of times we shy away from it and go back to the mindset of "I am just doing what I have always done." The beauty of athletic training is that we are always learning. We are never at a standstill, we are lifelong learners. Also, having an inclusive mindset. Maybe one of your patient populations is not being well served, so having awareness is a crucial skill. Next, basically provide grace. Understand that your patients may not understand what you are saying. They may not understand what athletic trainers do because they have not been around them. They may come in and they are very independent, and we are trying to educate them 
and do not understand why they do not understand. So, we have to provide grace but also ask for grace in this case. The last skill I would say is patience. Understand that this is a process that is new for a lot of athletic trainers. Have patience with your colleague, but ask for patience in return as well.

Decker: I agree with Shaketha. I also think the biggest factor is going to be soft skills. It is not going to be the tangible skills you learn in your athletic training program. It is going to be soft skills that you have and you continue to develop as a professional. Those are the most important factors to serving patients in the LGBTQ+ community. It goes back to what we have talked about regarding providing patient-centered care. There are no two patients within the LGBTQ+ community are the same. You may be treating two gay men that may identify similarly from a sexual orientation standpoint, they are going to have individual needs. It is critical to understand those needs and factors about our patients and their individual preferences throughout all of their care. We also need to move away from "treating all patients the same" regardless of their individual factors and differences. I think people have good intentions when they say that, but the reality is you are not being patient centered when you are treating every patient the same. When we take those individual factors into account, we are truly being patient centered and we can understand the unique aspects of the patient's needs.

Cage: What advice do you have for your fellow athletic trainers as we moved forward as a profession and try to uphold our responsibilities as healthcare providers to provide quality healthcare to all of our patients regardless of their demographic?

Pierce: Do not make assumptions. Do not assume every patient and their situation are the same. Do not assume that two patients' households are run the same just because they come from the same cultural background. Everyone is different. Make sure you ask questions. Try not to be offensive. If you have a question you need to ask but are worried it might be offensive, it might help to pose it as "May I ask this question, this is something I would like to know to better serve you." Next, do not pass judgement on the athlete. Whatever their situation is, do not judge them. Meet them where they are and try to make sure that you are providing patient centered care. Make sure we uphold the role as liaison for our patients. We are there to treat, we are there to serve as a liaison between our patients and our clinics. Make sure we do not feed into a bias we know may be held against the patient we are serving.

Decker: I think the first thing that we all have to do, regardless of our experiences, is to constantly self-reflect on the NATA Code of Ethics and the Board of Certification Standards of Professional Practice. Those are our guidelines to being the best, most inclusive, and competent healthcare providers that we can be. Instead of just assuming that we are doing those things, we should always go back to those and do an audit of ourselves to truly identify if we are upholding those guidelines to the best of our ability. Beyond that, it really starts with understanding and addressing our own biases. We have a responsibility to be inclusive healthcare providers. We are not only responsible for ourselves, but we are responsible for those around us as well. I think it is important that within that understanding and audit that we are doing, that we are continually committing to ourselves and our profession that we are going to hold others accountable as well as ourselves.

Cage: What are some ways members of SWATA and other districts can get involved to help your committees and committees like them?

Pierce: Definitely support our committee efforts. The biggest thing with Ethnic Diversity Advisory Committee is that every year we aim to have an education event and a community service or project. With that, when there is a sign up form for our projects, do not be afraid to sign up and 
participate. Do not assume that the project is only for ethnically diverse athletic trainers. The committee aims to serve ethnically diverse populations, but our committee projects are a representation of every athletic trainer in SWATA. Next, attend education sessions. Do not assume that just because you see title, that it does not include you. Do not assume from the title of a presentation that you cannot learn anything from it just because you feel you are already culturally competent and inclusive. There is always something new to learn. Too often people assume that a presentation with the topic of diversity or inclusion is not for them. We need everyone to be there. Make sure that you want to include yourself on what there is to learn. Also, sign up to be a volunteer on the volunteer list. Even if you are not on our committee, you may still be able to serve in other ways. When you see us in the exhibit hall, come over and see how you can be involved. In the month of March we usually highlight athletic trainers. When we send out those forms, some people are still in the mindset of "Well, I am not ethnically diverse; this is not for me." You do not have to be ethnically diverse to participate, March is National Athletic Training Month. We want to make sure that we highlight everyone. When we try to provide unity and break down those walls, we want to remove as many obstacles as possible.

Decker: The first two steps to take are attending lectures, workshops, and events and consistently staying up to date with the committee and the committee's efforts. A lot of this information is changing rapidly. Make sure that you are constantly attending those events. Also, sign up to volunteer. You do not have to serve as a committee member. There are so many ways to get involved. Reach out to the committee and see if there are side volunteer opportunities. Lastly, I think beyond just the committee or the scope of the athletic training profession I would encourage people to get involve at your school or organization. I had a colleague who completed
Safe Space Training and then reached out to me and said "Our athletic department is not as inclusive. I am worried I am not going to be able to make as big of an impact as I had hoped." My advice to her was to explore her campus environment and determine if she could make an impact outside of just the athletic department. This also goes into your community. If you can volunteer in your community, that is indirectly helping the initiatives of the committee to try to make our profession more inclusive. If we have a community that is safer and inclusive, people in the LGBTQ+ community can feel safer being their true and authentic selves.

Cage: What is one step athletic trainers could take today to make their clinics more inclusive?

Pierce: Work to understand the demographic characteristics of the patients you are serving. In my clinic, I serve a lot of Hispanic and Latinx patients. One thing I did was making sure I have physical forms in English and Spanish. This provides a more inclusive environment right from the start. This helps the patient come into the room and not feel that the room is not inclusive of them, and it creates a safe space.

Decker: Have something visible that shows that you run an inclusive facility. I do not think this is the most important step to take, but I do think seeing those visible images makes people feel safer. Maybe it is a Safe Space sticker or a Pride sticker, but it might help people let their guard down. That is a very superficial step, so I think there needs to be more to that. I think you have to actually act on those images and show people that you are inclusive beyond just showing them. Other additions could be displaying a non-discrimination policy, and having a zero tolerance policy to anything other than inclusivity in your facility from everyone who walks in the door. 